\title{
Researches concerning the hydraulic oil degradation process in gear pumps
}

\author{
Alexandru Daniel Marinescu ${ }^{1}$, Alexandru Valentin Radulescu ${ }^{2}$, Irina Radulescu ${ }^{2}$ \\ ${ }^{1}$ Hydraulics and Pneumatics Research Institute INOE 2000- IHP, Bucharest, Romania \\ ${ }^{2}$ University POLITEHNICA Bucharest, Romania \\ E-mail: alexandru.radulescu@ upb.ro
}

\begin{abstract}
The paper investigates the degradation and contamination level of the hydraulic oil used on an endurance stand for testing two different types of gear pumps. Experimental results have been obtained using a Brookfield CAP2000+ viscometer, for determining the oil rheological parameters. Also, the paper presents the Parker CM Laser Particle Analyser used for measuring the size and density of the oil wear particles. The results focused on lubricant analysis represent practical ways to apply predictive and proactive maintenance for hydraulic gear pumps, but also for other hydrostatic equipment.
\end{abstract}

Ketwords: gear pumps, oil, degradation

\section{Introduction}

Oil analysis has always been considered as one of the basic procedures of preventive maintenance, with focuses, in particular, on determining the optimum time needed to replace oils and lubricants. It should be noted that modern tools used in industrial maintenance can perform measurements and analyses in real time, in situ and online, but the analysis of oil and lubricant samples is based on laboratory services [1], [2]. The analysis of hydraulic oils can be successfully included in testing procedures, specific to predictive maintenance that examine the safety of machines and equipment in various fields of activity [3].

The maintenance of lubrication systems in machines relies on periodic inspection and lubricant change [4], [5]. Hard contaminants or soft particles appear in the hydraulic oil of the machines, but also air, water, heat or various substances can influence its properties. Researches in the direction of establishing the link between oil contamination with particles and the occurrence of failures in hydraulic drive systems are now more and more numerous [6].

In this respect, we can mention the research carried out by Stamatios S. Kalligeros [7] on used oils of hydraulic lifts, or by Polychronis S. Dellis [8], on the automatic spectrometry of hydraulic oils used in aircraft in order to prevent engine failures. Alabi and the collaborators predict the failure of an equipment, with the help of a real-time lubricating oil analysis [9]. Amin Almasi described particle analysis methods and an online oil monitoring and highlights that substantial savings can be achievable through an effective oil analysis program [10]. Tatiana Minav and the collaborators made an evaluation of an electro-hydraulic system and a discussion on the usage of hydraulic oil by non-road mobile working machines in sub-zero conditions [11].

In many situations, hydraulic gear pumps are contaminated with various solid particles. These produce fine, abrasive traces of wear, normally observable only under a microscope. Particles with a diameter of less than $5 \mu \mathrm{m}$ are very abrasive and as they change to a muddy appearance over time, they can endanger pumps and their components. The uncontrolled presence of such particles must be avoided in hydraulic installations, because they act as a grinding medium. At INOE 2000-IHP Bucharest, 
researches in this direction was conducted by A. D. Marinescu and collaborators first with the help of the infrared thermography method [12], and then with the help of the vibration method, [13].

\section{Experimental stand and methodology}

This article follows the two predictive maintenance methods shown above, used in the monitoring of hydraulic gear pumps, through joint researches initiated by specialists and professors from INOE 2000 Bucharest and University POLITEHNICA of Bucharest concerning oil analysis.

In the year 2020, at the Romanian company SC Hesper SA Bucharest, two types of hydraulic gear pumps, in endurance tests were monitored, by the paper authors. According to the manufacturer's coding, these pumps, of 05 series are the following:

- HP0505-0,5+1,5-1-0,2-6-C-06-2, 11 UA (P1 pump), Fig. 1.

- BHP 05-05-010 UB, 01 TC (P2 pump), Fig. 2.

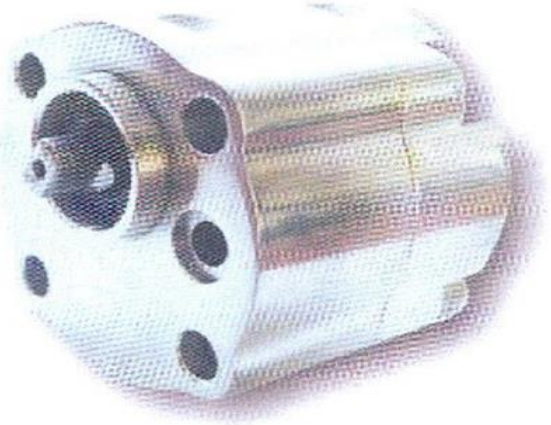

Figure 1. P1 Pump [14]

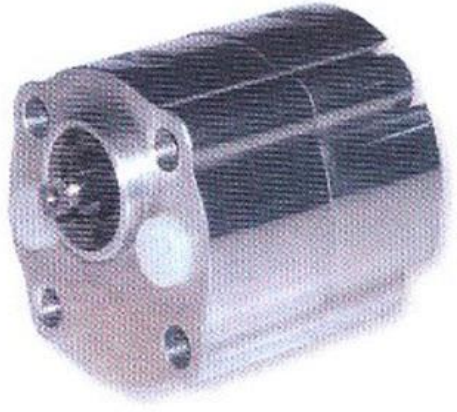

Figure 2. P2 Pump [14]

The endurance stands of the pumps (Fig. 3 and Fig. 4) are equipped with three hydraulic filters to ensure the quality of the working fluid, more precisely a H46 EP oil.

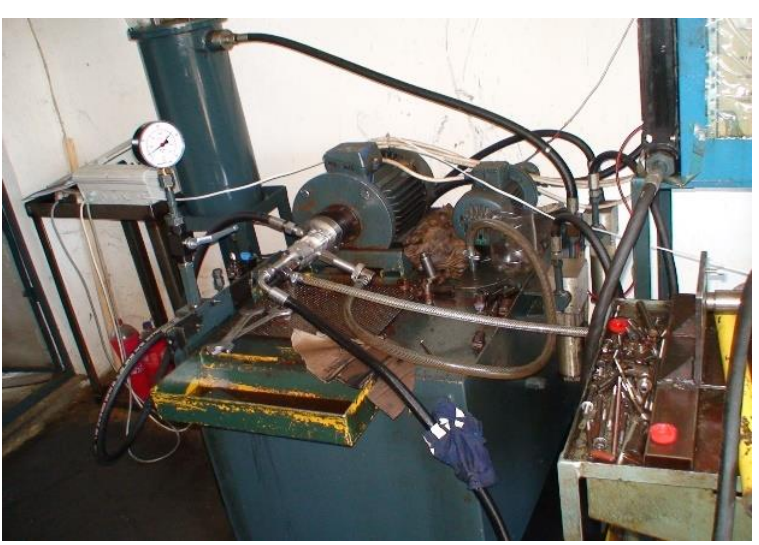

Figure 3. P1 pump stand endurance

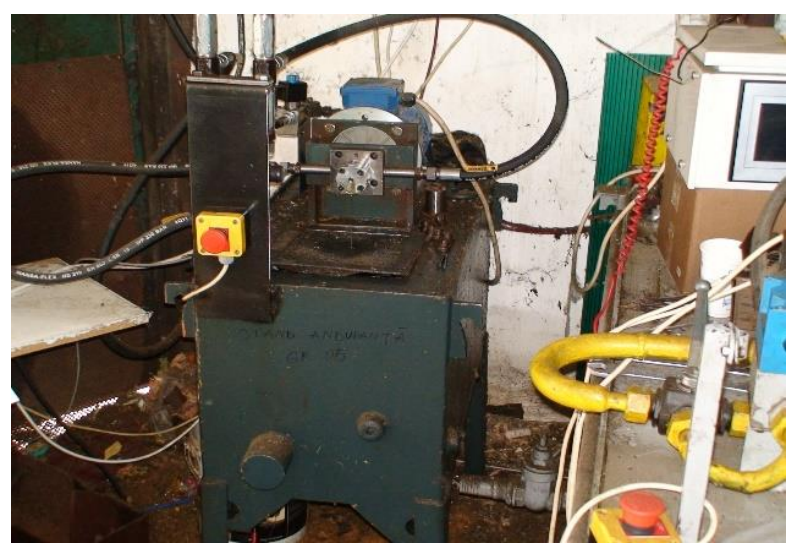

Figure 4. P2 pump stand endurance

The H46 EP mineral oil, is an additive hydraulic oil for extreme pressure, and meets the requirements of the specifications: DIN 51524/ Part 2 HLP, AFNOR NF E 48-603 HM, Sperry Vickers I-286-S, Denison Filterability TP 02100, US Steel 127, STAS 12023-82 [15].

In order to monitorise the hydraulic gear pumps, two different ultramodern working instruments were used, namely: the Parker CM laser particle analyser (Fig. 5) and the Brookfield CAP2000+ viscometer (Fig. 6). 


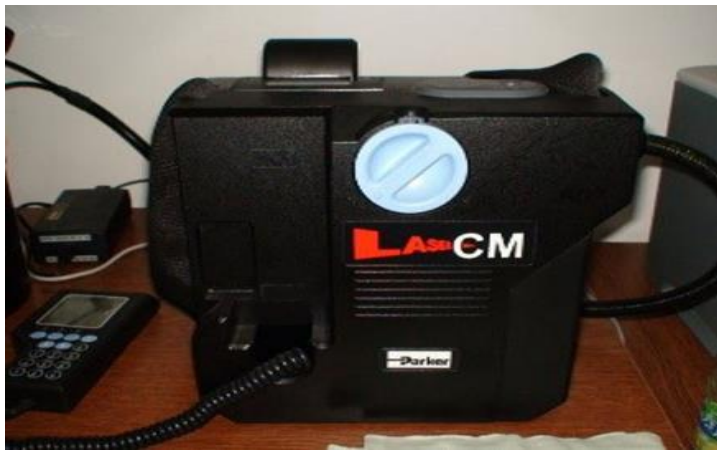

Figure 5. Parker Laser CM particles analyzer

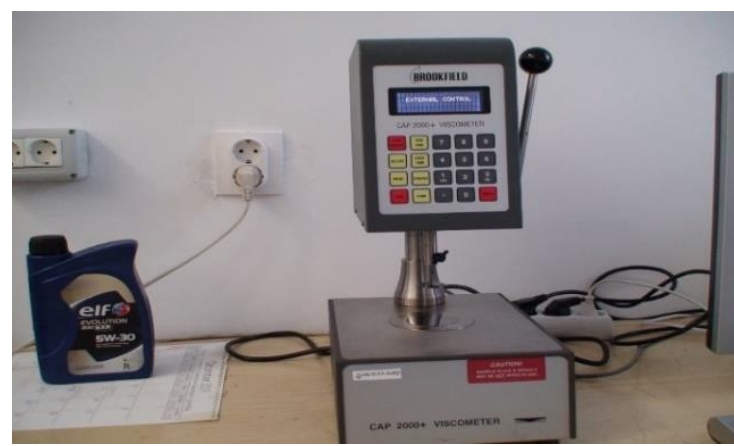

Figure 6. Brookfield CAP2000+ viscometer

The Parker CM laser particle analyser (fig. 5) allows a 2-minute contamination test procedure. It's made of a particle monitor designed to be used in the field. Multi-standard ISO,NAS, AS4059E and GOST 17216 cleanliness reporting, data entry, data graphing and integral printing are all standard on this world proven contamination monitor.

The main product features are indicated according to the technical sheet of the manufacturer [16]:

- Special 'diagnostics' are incorporated into the icountLaserCM microprocessor control to ensure effective testing.

- Routine contamination monitoring of oil systems with icountLaserCM saves time and saves money.

- Contamination monitoring is possible during applicaton operation - icountLaserCM saves on production downtime.

- Data entry allows individual equipment test log details to be recorded.

- Data retrieval of test results from memory via hand set display.

- Automatic test cycle logging of up to 300 tests can be selected via hand set display.

- Totally portable, can be used as easily in the field as in the laboratory.

- Automatic calibration reminder.

- Instant, accurate results achieved with a 2 minute test cycle.

- Data entry allows individual equipment footprint record.

- Data graphing selectable via the integral printer.

- Auto 300-test cycle logging via LCD handset input.

- RS232 to USB computer interface.

- Limit level output to control peripheral equipment such as off-line filtration via internal relay limit switches.

- Auto-testing allows for the conducting of automatic sequencing tests on flushing systems for example.

- Memory access gives test search facility

The Brookfield CAP2000+ viscometer (Fig. 6) is a compact analysis laboratory instrument that can be used to test products over a wide range of temperatures and viscosities, and which has the following characteristics:

- - viscosity range: $0.2 \ldots .15$ Poise;

- - shear rate: $10 \ldots 13 \mathrm{~s}^{-1}$;

- - temperature $5-75^{\circ} \mathrm{C}$, or $50-235^{\circ} \mathrm{C}$;

- $\quad$ rotation speed 5-1000 rpm;

- $\quad$ small sample $<1 \mathrm{ml}$;

- $\quad$ integral temperature control;

- - an optional software CAPCALC 32, for complete control and data analysis. 


\section{Results}

\subsection{Analysis of contaminant particles}

With Parker CM laser particle analyser, experiments were performed separateley for the oil samples taken from the endurance stands of $\mathrm{P} 1$ and $\mathrm{P} 2$ pumps. The analyzer printer provided for each performed analysis a special receipt indicating the number of solid contaminant particles in the oil samples, having a diameter $d$ in the range of $(4 \ldots 70) \mu \mathrm{m}$. All the obtained results from the analysis of the oil samples of the two pumps P1 and P2 were listed separately in the Table 1 and Table 2.

Table 1. Monitoring of P1 pump.

\begin{tabular}{|c|c|c|c|c|c|c|c|}
\hline \multirow{2}{*}{$\begin{array}{c}\text { Test } \\
\text { Number }\end{array}$} & \multirow{2}{*}{ Date } & \multicolumn{6}{|c|}{ Number of solid contaminants, in $100 \mathrm{ml}$ oil samples } \\
\hline & & $\begin{aligned} \mathrm{d}= & (4 \ldots 6) \\
& \mu \mathrm{m}\end{aligned}$ & $\begin{array}{l}\mathrm{d}= \\
(6 \ldots 14) \\
\mu \mathrm{m}\end{array}$ & $\begin{array}{c}\mathrm{d}= \\
(14 \ldots 21) \\
\mu \mathrm{m}\end{array}$ & $\begin{array}{l}\mathrm{d}= \\
(2138) \\
\mu \mathrm{m}\end{array}$ & $\begin{array}{c}\mathrm{d}= \\
(3870) \\
\mu \mathrm{m}\end{array}$ & $\begin{array}{c}\mathrm{d}>70 \\
\mu \mathrm{m}\end{array}$ \\
\hline 1 & $05 / 02 / 2020$ & 1403664 & 974014 & 259064 & 116878 & 18192 & 1125 \\
\hline 2 & $07 / 02 / 2020$ & 1366371 & 887264 & 96842 & 16578 & 4192 & 259 \\
\hline 3 & $17 / 02 / 2020$ & 1400614 & 905721 & 143964 & 45907 & 5521 & 341 \\
\hline 4 & $24 / 02 / 2020$ & 1327150 & 759992 & 52257 & 12528 & 1600 & 98 \\
\hline 5 & $06 / 03 / 2020$ & 1606700 & 926778 & 65307 & 13828 & 1664 & 102 \\
\hline 6 & $13 / 03 / 2020$ & 1585857 & 821485 & 23807 & 3535 & 700 & 43 \\
\hline 7 & $20 / 03 / 2020$ & 1630407 & 868892 & 26871 & 4335 & 607 & 37 \\
\hline 8 & $15 / 07 / 2020$ & 2039592 & 775442 & 12742 & 2671 & 485 & 30 \\
\hline 9 & $17 / 07 / 2020$ & 2611414 & 1455735 & 76507 & 10264 & 857 & 53 \\
\hline
\end{tabular}

Table 2. Monitoring of P2 pump

\begin{tabular}{cccccccc}
\hline $\begin{array}{c}\text { Test } \\
\text { Number }\end{array}$ & Date & \multicolumn{6}{c}{ Number of solid contaminants, in 100 ml oil samples } \\
\cline { 3 - 8 } & & $\mathrm{d}=(4 \ldots$ & $\mathrm{d}=$ & $\mathrm{d}=$ & $\mathrm{d}=$ & $\mathrm{d}=$ & $\mathrm{d}>70$ \\
& & $6) \mu \mathrm{m}$ & $(6 \ldots 14)$ & $(1421)$ & $(2138)$ & $(3870)$ & $\mu \mathrm{m}$ \\
& & & $\mu \mathrm{m}$ & $\mu \mathrm{m}$ & $\mu \mathrm{m}$ & $\mu \mathrm{m}$ & \\
\hline 1 & $04 / 06 / 2019$ & 1308178 & 400542 & 9085 & 3185 & 1121 & 69 \\
2 & $10 / 06 / 2019$ & 1430071 & 1094278 & 457542 & 210392 & 59314 & 3669 \\
3 & $10 / 06 / 2019$ & 1363457 & 1024407 & 422328 & 189150 & 52414 & 3242 \\
4 & $10 / 06 / 2019$ & 1559421 & 487650 & 13921 & 4357 & 1007 & 62 \\
5 & $10 / 06 / 2019$ & 1561271 & 487835 & 12350 & 3542 & 764 & 47 \\
6 & $24 / 06 / 2019$ & 1349300 & 383728 & 32428 & 12764 & 3292 & 203 \\
7 & $24 / 06 / 2019$ & 1307342 & 345814 & 34164 & 13735 & 3835 & 237 \\
8 & $02 / 07 / 2019$ & 1346250 & 408171 & 45650 & 17007 & 5600 & 346 \\
9 & $02 / 07 / 2019$ & 1336057 & 408578 & 47250 & 16864 & 5357 & 331 \\
10 & $11 / 07 / 2019$ & 1236678 & 291721 & 7678 & 2814 & 642 & 39 \\
11 & $23 / 07 / 2019$ & 1248728 & 334685 & 9764 & 3192 & 585 & 36 \\
12 & $22 / 08 / 2019$ & 1243300 & 314607 & 12557 & 4557 & 864 & 53 \\
13 & $05 / 09 / 2019$ & 1152842 & 319300 & 27464 & 11514 & 2278 & 140 \\
14 & $10 / 09 / 2019$ & 1154557 & 290657 & 13500 & 4957 & 914 & 56 \\
15 & $19 / 09 / 2019$ & 2453142 & 1339885 & 65164 & 13992 & 2121 & 131 \\
16 & $27 / 09 / 2019$ & 893692 & 216971 & 10657 & 4064 & 850 & 52 \\
17 & $18 / 10 / 2019$ & 1062800 & 389142 & 31521 & 11871 & 2635 & 163 \\
18 & $01 / 11 / 2019$ & 737407 & 236314 & 19035 & 7935 & 2107 & 130
\end{tabular}




\begin{tabular}{cccccccc}
\hline $\begin{array}{c}\text { Test } \\
\text { Number }\end{array}$ & Date & \multicolumn{6}{c}{ Number of solid contaminants, in 100 ml oil samples } \\
\cline { 3 - 8 } & & $\begin{array}{c}\mathrm{d}=(4 \ldots \\
6) \mu \mathrm{m}\end{array}$ & $\begin{array}{l}\mathrm{d}= \\
(6 \ldots 14) \\
\mu \mathrm{m}\end{array}$ & $\begin{array}{c}\mathrm{d}= \\
(1421) \\
\mu \mathrm{m}\end{array}$ & $\begin{array}{l}\mathrm{d}= \\
(2138) \\
\mu \mathrm{m}\end{array}$ & $\begin{array}{c}\mathrm{d}= \\
(3870)\end{array}$ & $\begin{array}{c}\mathrm{d}>70 \\
\mu \mathrm{m}\end{array}$ \\
\hline & & & & & & & \\
19 & $22 / 11 / 2019$ & 591578 & 164757 & 6792 & 2485 & 550 & 34 \\
20 & $13 / 12 / 2019$ & 1420257 & 1049650 & 350835 & 149642 & 11092 & 686 \\
21 & $18 / 12 / 2019$ & 1124900 & 623764 & 54964 & 15871 & 3242 & 200 \\
22 & $10 / 01 / 2020$ & 1016107 & 578250 & 52542 & 23178 & 10135 & 626 \\
23 & $05 / 02 / 2020$ & 1151692 & 550957 & 21528 & 7157 & 2542 & 157 \\
24 & $07 / 02 / 2020$ & 1188914 & 690671 & 61157 & 14485 & 2942 & 181 \\
25 & $17 / 02 / 2020$ & 1144214 & 637850 & 40507 & 7107 & 2300 & 142 \\
26 & $24 / 02 / 2020$ & 957750 & 444607 & 20521 & 7214 & 2414 & 149 \\
27 & $06 / 03 / 2020$ & 1335950 & 681400 & 40657 & 10650 & 2314 & 143 \\
28 & $13 / 03 / 2020$ & 1353321 & 691785 & 48628 & 23014 & 15814 & 978 \\
29 & $20 / 01 / 2020$ & 1279535 & 640528 & 53292 & 23300 & 9357 & 578 \\
30 & $15 / 07 / 2020$ & 1558407 & 589071 & 67414 & 28078 & 4207 & 260 \\
31 & $08 / 09 / 2020$ & 1080121 & 324278 & 28700 & 12335 & 2442 & 151 \\
\hline
\end{tabular}

The overtime evolution of oil contaminants particles number function of their diameters is graphically presented, using an unique coordinate system. Thus, the diagrams corresponding to the PI and P2 pump monitoring were drawn in Fig. 7, respectively in Fig. 8. The construction of the pump P2 diagrams was done taking into account only nine representative tests for its monitoring, registered in Table 2.

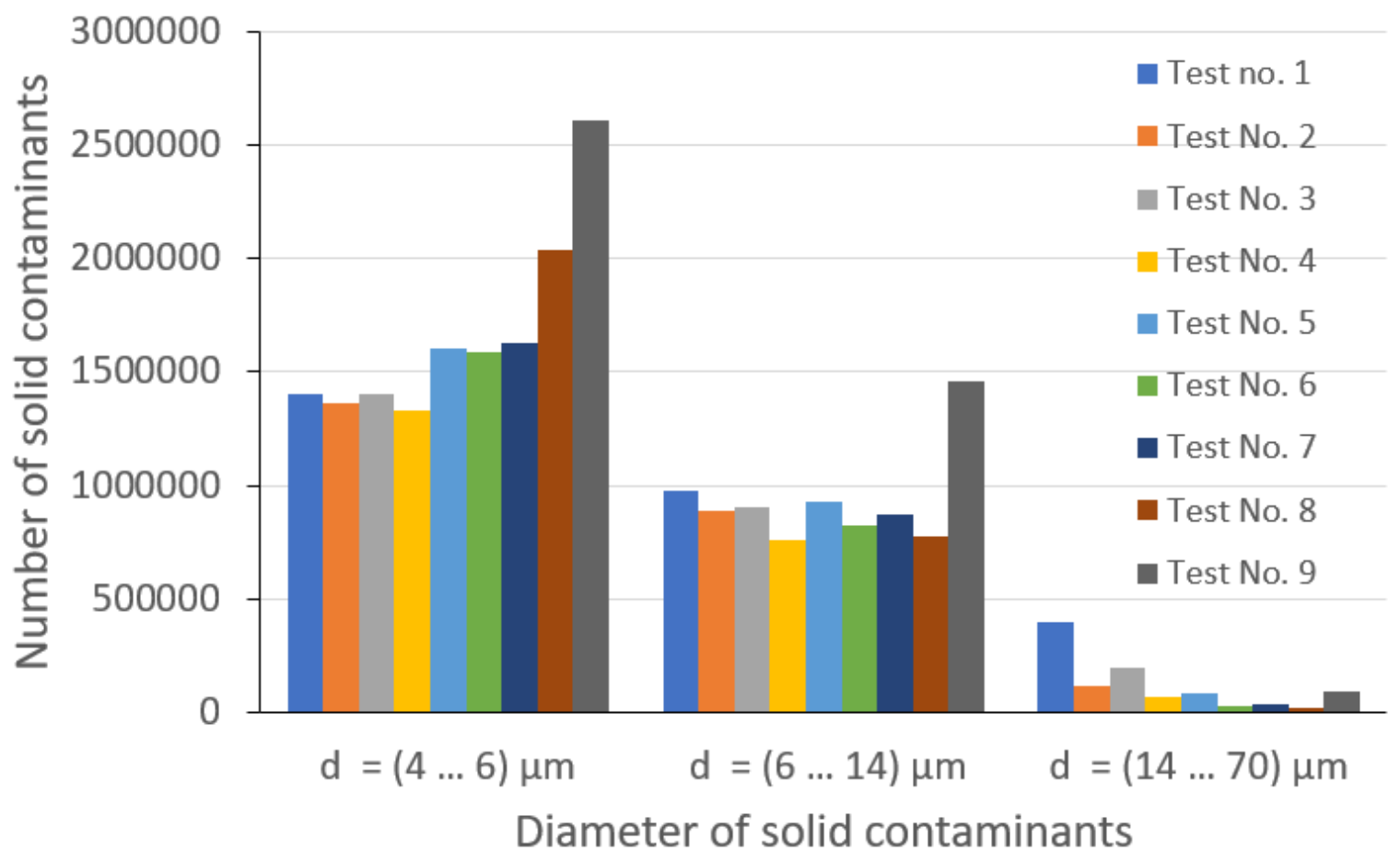

Figure 7. P1 pump over time oil contaminants evolution 


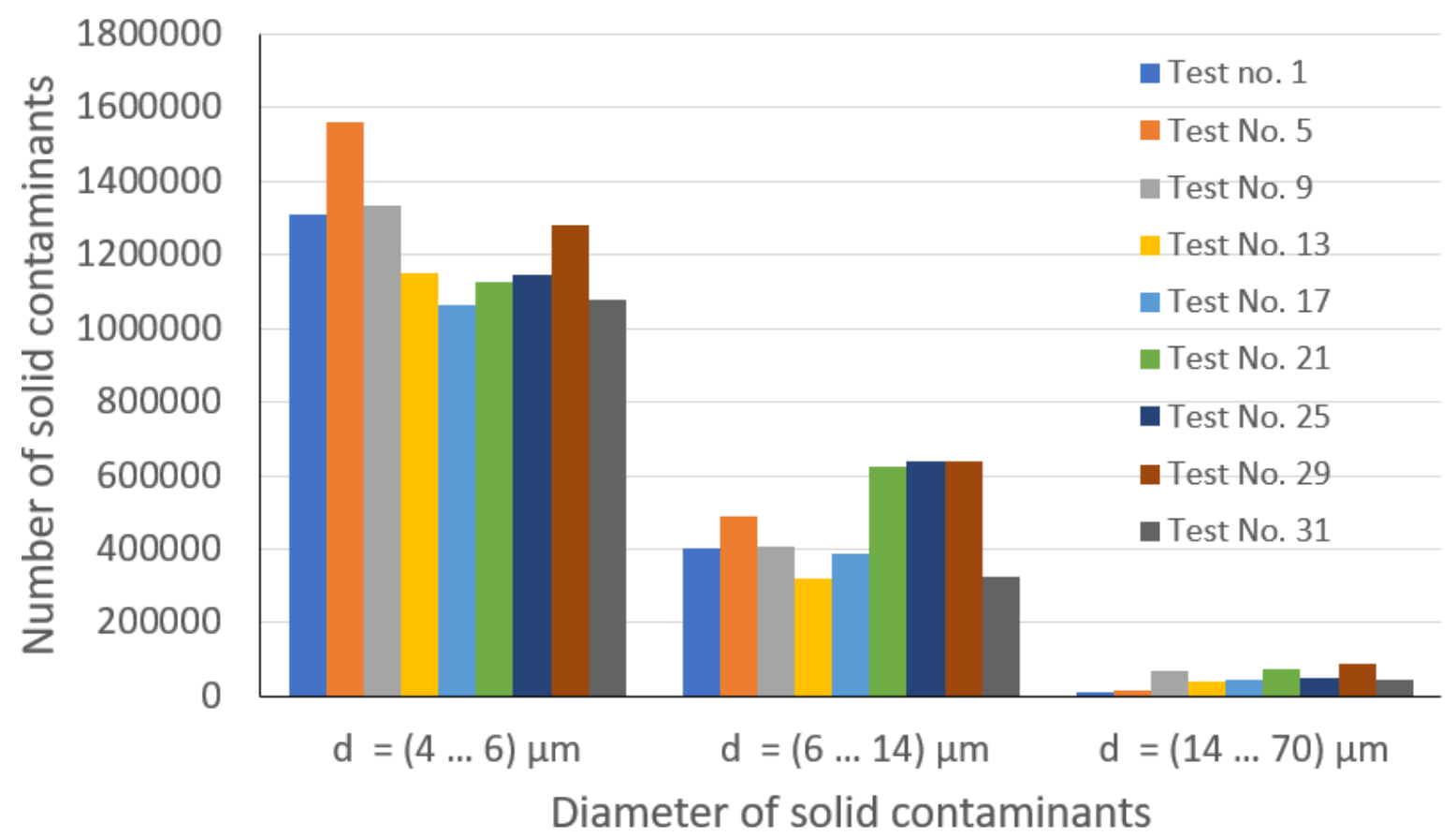

Figure 8. P2 pump over time oil contaminants evolution

\subsection{Rheological tests for fresh and used oil samples}

Monitoring of the oil state in a drive unit can be useful for assessment of its damage and defects. One of the most important parametres of lubricating oil is its viscosity. Excessive changes in the oil viscosity value can indicate damage of the drive unit and/or its defects [17], [18]. Significantly lower viscosity can indicate the presence of fuel or coolant in it [19].

The use of the Brookfield rotational viscometer with cone-disk working geometry, allowed the determination of the analyzed oil samples rheological properties. Fig. 9 shows the principle on which the viscometer is designed and made. The main parts of the viscometer are the cone and the disk, between which the oil sample is inserted. A rotational motion with angular velocity $\omega$ is imprinted on the cone; the disk is fixed. The viscometer is provided with transducers necessary for oil flow measurement: shear rate, shear stress and temperature.

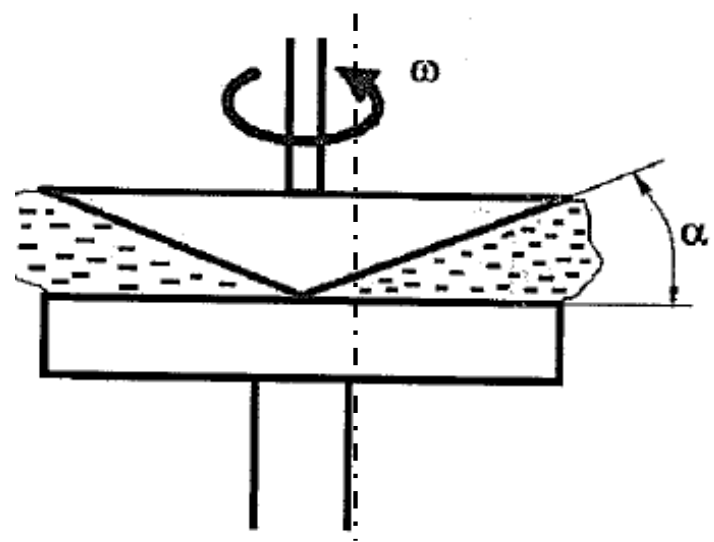

Figure 9. Rotational viscometer principle 
Regarding the rheological experiments, three types of tests were performed:

- Test for homogenization;

- Test for determining the parameters of the rheological model;

- Test for variation of the oil apparent viscosity with temperature.

The test for homogenization was performed for a H46 EP fresh oil sample (Fig. 10). The homogenization test is a time test, done at different speeds of the viscometer, in order to establish the necessary time for measurement stabilization. This time is necessary for designing the rheological experiment The following results were obtained (Table 3):

Table 3. Time for homogenization

\begin{tabular}{cc}
\hline Rotation speed, rpm & Time, $\mathrm{s}$ \\
\hline 100 & 25 \\
200 & 20 \\
500 & 25 \\
\hline
\end{tabular}

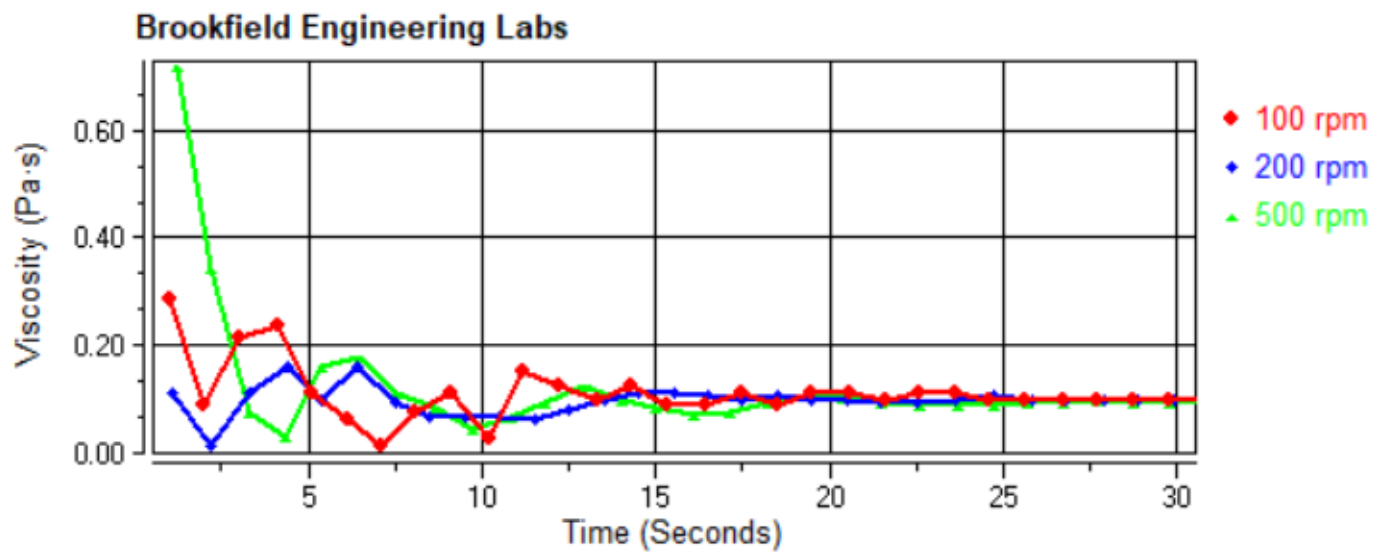

Figure 10. Homogenization time for fresh oil sample, at different rotation speeds

To determine the lubricant rheological model for fresh oil and used oil on P1 and P2 pumps, it was used an "imposed velocity gradient" test, with the variation limits $200 \ldots 2000 \mathrm{~s}^{-1}$, at a constant temperature of $20^{\circ} \mathrm{C}$ and a homogenization time given by Table 3 . The tests were carried out with a load up to $2000 \mathrm{~s}^{-1}$ and unloading up to $200 \mathrm{~s}^{-1}$, in order to highlight the effects of lubricant thixotropy. The obtained rheograms are presented in Figure 11.

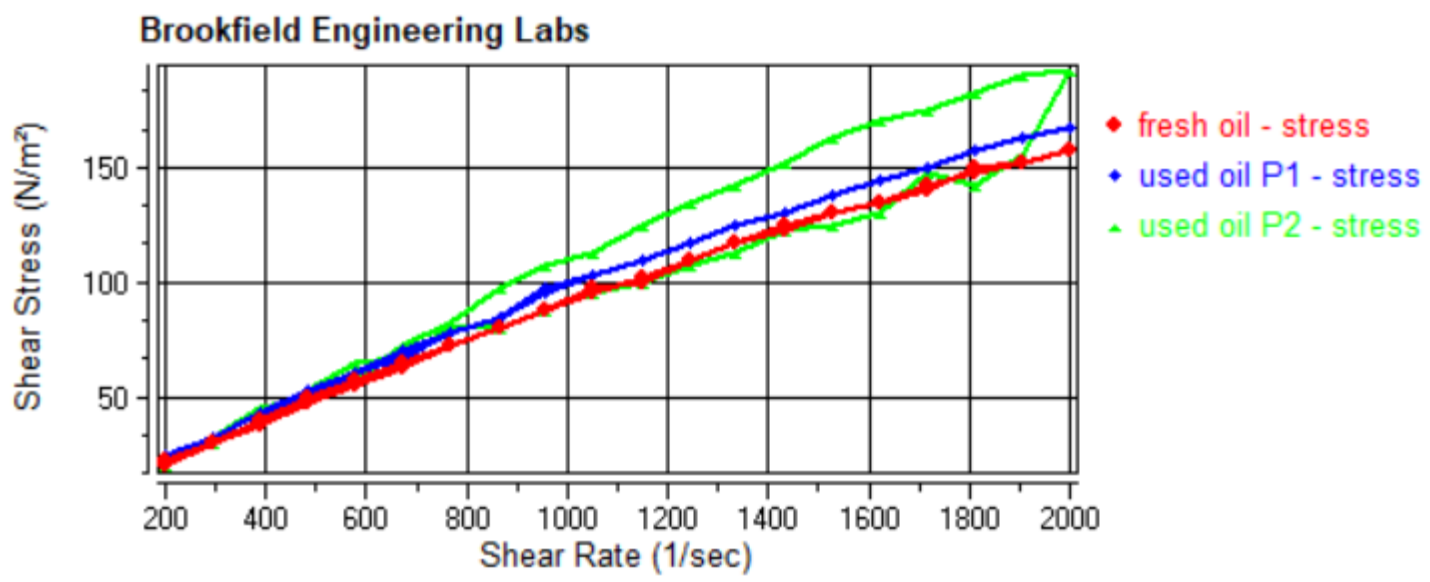

Figure 11. Rheograms for tested oils 
The lubricant rheological parameters are calculated by using the rheometer software, for power law rheological model (Table 4):

$$
\tau=m\left(\frac{d u}{d y}\right)^{n}
$$

where:

$m$ - consistency index (which is equivalent to the Newtonian fluid viscosity);

$n$ - flow index (equal to 1 if the fluid is Newtonian).

Table 4. Rheological parameters for fresh and used oil samples

\begin{tabular}{lccccc}
\hline \multirow{2}{*}{ Oil state and type } & \multicolumn{2}{c}{ Newtonian model } & \multicolumn{3}{c}{ Power law model } \\
\cline { 2 - 6 } & $\begin{array}{c}\text { Viscosity, } \\
\mathrm{Pa} \cdot \mathrm{s}\end{array}$ & $\begin{array}{c}\text { Correlation } \\
\text { coefficient, } \%\end{array}$ & $\begin{array}{c}\text { Consistency index, } \\
\mathrm{Pa} \cdot \mathrm{s}^{-\mathrm{n}}\end{array}$ & $\begin{array}{c}\text { Flow } \\
\text { index }\end{array}$ & $\begin{array}{c}\text { Correlation } \\
\text { coefficient, \% }\end{array}$ \\
\hline H46 EP fresh oil & 0.085 & 97.8 & 0.210 & 0.877 & 97.9 \\
P1 Pump used H46 EP oil & 0.090 & 97.5 & 0.250 & 0.861 & 98.2 \\
P2 Pump used H46 EP oil & 0.095 & 92.3 & 0.177 & 0.915 & 91.4 \\
\hline
\end{tabular}

To determine the apparent viscosity variation versus temperature for analyzed lubricants, there were made tests for an imposed velocity gradient of $1000 \mathrm{~s}^{-1}$. The obtained rheogram is presented in Figure 12 .

\section{Brookfield Engineering Labs}

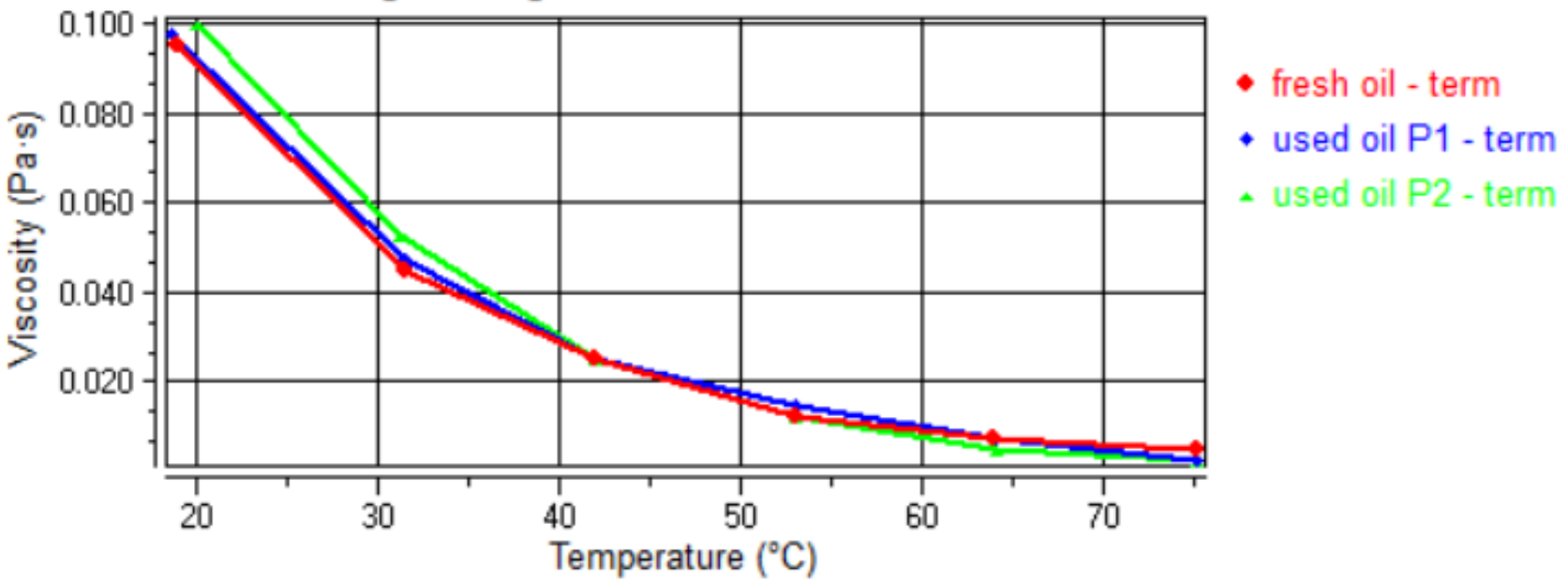

Figure 12. Variation of the apparent viscosity versus temperature

\section{Discussions}

The analysis of the diagrams for pump P1 (Figure 7) shows that the number of oil contaminant particles with diameter $d$ in the range (4 .. 21) $\mu \mathrm{m}$ decreased throughout the endurance cycle, while the number of contaminant particles, having the diameter $d$ in the range (38 .. 70) $\mu \mathrm{m}$, is relatively constant. The contribution of particles with diametres $d$ in the range $(4 \ldots 21) \mu \mathrm{m}$ was a major one, while the contribution of particles with diameters $d$ in the range (38 .. 70) $\mu \mathrm{m}$ was negligible.

Concerning the pump P2, the same analysis (Figure 8) establish that the number of oil contaminant particles with $d=(4 \ldots 6) \mu \mathrm{m}$, decreased throughout the endurance cycle, while the number of contaminant particles having $d=(14 \ldots 70) \mu \mathrm{m}$ is relatively constant. The contribution of particles with diametres $d=(4 \ldots 6) \mu \mathrm{m}$ was a major one, while the contribution of particles with diameters $d=$ (14 ... 70) $\mu \mathrm{m}$ was negligible. 
Regarding the rheological tests, it can observe that the characteristic rheological model for fresh oil and used oil on P1 pump is the power law model, while for used oil on and P2 pump is the Newtonian model, with a high correlation coefficient. For the fresh oil and used oil on P1 pump, it hasn't been observed any thixotropy phenomenom. This shows that the structure of both oils is very stable. On the other hand, the thixotropy for $\mathrm{P} 2$ used oil pump is very pronounced, which means that its structure is relatively unstable and heterogeneous.

Another important observation which results from rheological test is that the apparent viscosity of the lubricant, in the range of $20 \ldots 40^{\circ} \mathrm{C}$, increases once with the oil wear degree. Once the temperature is rising, the difference between the values of the viscosity for fresh or used oils becomes insignificant.

\section{Conclusions}

In this paper the authors studied the influence of solid contaminant particles on the wear of two hydraulic gear pumps on the endurance stands, using two modern laboratory appliances, namely a Parker analyser and a Brookfield viscometer.

- Using the Laser CM Parker analyzer, the researchers established the contribution of contaminant particles to the wear of the $\mathrm{P} 1$ and $\mathrm{P} 2$ pumps, depending on their diameters:

- For P1 pump, particles with diametres $\mathrm{d}>(4,6,14,21) \mu \mathrm{m}$ were more numerous, and thus they used more the pump, while the number of particles with diameters $d>(38,70) \mu \mathrm{m}$ was negligible, so they used the pump less.

- For P2 pump, the particles with diametres $\mathrm{d}>(4,6) \mu \mathrm{m}$ were more numerous, and thus they used more the pump, while the number of particles with diameters $d>(14,21,38,70) \mu \mathrm{m}$ was negligible, so they used the pump less.

- Using the Brookfield CAP2000 + viscometer, there was an increase in apparent viscosity of the used oil in P1 and P2 pumps, which is explained by the increase of the contaminant particles number, after runing-in. The following rheological models were chosen: power law for H46 EP fresh oil sample and P1 pump used oil sample; Newtonian model for the P2 pump used oil sample.

Thus, the interest parameters for evaluation of the P1 pump oil contamination were the consistency index and the flow rate respectively, but for evaluation of the P2 pump oil contamination, the dynamic viscosity was the main indicator of the contaminants appearance.

- The experiments described in this paper support the predictive maintenance activities in the field. Thus, the laboratory performed analysis of the oil allowed the quantification of the impurities number, with a direct effect on the wear of the hydraulic gear pumps, but also the indication of the rheological models to be followed for their good modeling.

\section{References}

[1] Mačužić I and Jeremić B 2004 Proactive Approach to Oil Maintenance Strategy Tribology in Industry 26 (1\&2) pp 27-31

[2] Holmberg K and Erdemir A 2015 Global impact of friction on energy consumption, economy and environment Fme Transactions 43 (3) pp 181-185

[3] Bakić G M, Đukić M B, Lazović T and Popović O D 2007 New methodology for monitoring and prevention of rotating parts failures Fme Transactions 35 (4) pp 195-200

[4] Fitch B Oil analysis explained (https://www.machinerylubrication.com/read /29598/oil-analysisreport) (accessed 27.04.2021)

[5] Yang C, Abanteriba S and Becker A 2020 A novel passive filtration system-lubricated gearboxes Sage Journals 234 (10) pp 1594-1604

[6] Dizdar S, Tomović R and Vučina A 2018 Lifetime estimate of pipe systems Applied Engineering Letters 3 (1) pp 13-19

[7] Kalligeros S S 2014 Predictive Maintenance of Hydraulic Lifts through Lubricating Oil Analysis Machines 2 pp 1-12

[8] Dellis P S 2019 The Automated Spectrometric Oil Analysis Decision Taking Procedure as a Tool to Prevent Aircraft Engine Failures Tribology in Industry 41 (2) pp 292-309 
[9] Alabi O, Wilson R, Adegbotolu U, Kudenhinbu S and Bowden S 2019: Realtime lubricating oil analysis to predict equipment failure Proceedinds of the SPE Offshore Europe Conference and Exhibition 2019 paper SPE-195708-MS

[10] Almasi A Oil analysis methods and lubrication monitoring (https://www.plantservices.com /articles /2014/oil-analysis-methods-lubrication-monitoring) (accessed 27.04.2021)

[11] Minav T, Heikkinen J, Schimmel T and Pietola M 2019 Direct Driven Hydraulic Drive: Effect of Oil on Efficiency in Sub-Zero Conditions Energies 12 (2) pp 219-226

[12] Marinescu A D, Cristescu C, Popescu T C and Safta C A 2017 Assessing the Opportunity to Use the Infrared Method for Predictive Maintenance of Hydrostatic Pumps Proceedings of the International Conference for Energy and Environment (CIEM) 2017 pp 270-274

[13] Marinescu A D, Safta C A, Popescu T C and Cristescu C 2018 Maintenance of Hydraulic Drive Systems via Vibroacoustic Diagnosis Proceedings of the International Multidisciplinary Conference „Professor Dorin Pavel, founder of the Romanian Hydropower Engineering” 2018 pp 247-256

[14] *** Products Catalogue SC HESPER SA Hydraulic gear pumps ( https://www.hesper.ro/ categorie-produs/pompe-si-motoare-cu-roti-dintate) (accessed 26.04.2021)

[15] *** Products Lukoil oil (https://www.sigma-distributie.ro/ulei-lukoil/lubrifianti-industriali/uleihidraulic/ulei--lukoil-h-100-ep/files/fisa_produs/1-4\%20HIDRAULICE\%20ADITIVATE \%20PENTRU\%20EXTREMA\%20PRESIUNE\%20H_EP.pdf) (accessed 26.04.2021)

[16] *** icountLaserCM20 Portable Particle Monitor (https://www.parker.com/Literature/ Hydraulic\%20Filter\%20Division\%20Europe/Websphere\%20Literature\%20Condition\%20M onitoring/icountLCM_serie.pdf) (accessed 27.04.2021)

[17] Balan C, Hamnelid L, Franco J M, Britton M, Callaghan P T, Bonneau D, Radulescu A V and Marin A 2000 The Rheology of Lubricating Grease (European Lubricating Grease Institute Publications)

[18] Radulescu I, Radulescu A V and Broboana D 2011 Rheological methods for evaluating the durability of industrial lubricants Journal of the Balkan Tribological Association 17 (1) pp 145-152

[19] Ryniewicz A M, Bojko L and Madej T 2014 Assessment of motor oil viscosity with the use of rotary viscometer Scientific bulletins of Silesian University of Technology 83 pp 1904-1910 